\title{
Labicom Labs 2015: Remote Laser Virtual and Remote Lab, Global Navigation Satellite Systems Virtual and Remote Lab, Microwave Amplifier Remote Lab
}

\author{
http://dx.doi.org/10.3991/ijoe.v12i04.5076 \\ Igor Titov ${ }^{1}$, Alexander Glotov², Igor Vlasov², Jakov Mikolnikov² \\ ${ }^{1}$ Labicom, Moscow, Russia \\ ${ }^{2}$ Bauman Moscow State Technical University (BMSTU), Moscow, Russia
}

\begin{abstract}
This paper briefly describes a few remote and virtual laboratories from BMSTU and Labicom at Labicom platform in 2015. Client side of the distributed network applications is shown. Main features and characteristic important from the point of view of remote lab design are discussed.
\end{abstract}

Index Terms-Labicom; remote/virtual laboratory; STEM; engineering education; e-learning.

\section{INTRODUCTION}

Despite a growing need of internet brokerage system and 'turn-key' software for on-line laboratories there is not even one that satisfies all different requirements and demands of laboratories' developers.

To address such needs the Labicom platform [1] was developed. Labicom provides remote and virtual labs with infrastructure, API and software packages, such as 'Labicom Connect' [2].

A few remote and virtual labs were created and added on top of Labicom software and infrastructure. Remote Laser Laboratory (RLL) [3]-[4] and Global Navigation Satellite Systems Laboratory (GNSSL) [5] were jointly developed by Labicom and BMSTU with existing laboratory resources of Radioelectronic Systems and Devices Department at BMSTU. Microwave Amplifier Remote Laboratory (MicroAmpRL) was developed by Labicom with the instruments provided by Keysight Technologies.

\section{GENERAL DESCRIPTION}

Labicom provides API for developers of on-line laboratories (remote and virtual). It also hosts laboratoryspecific client-side applications and generic ones like time reservation, group management etc. It relies on advanced Internet technologies and uses distributed multi-tier architecture for being able to provide as much flexibility, resources and usability as possible. Labicom also introduces commercial components and a business model for educational institutions and remote laboratories.

From the point of view of laboratory users (for example, students) Labicom is a web-site accessible via modern browser from any kind of device where an Internetbrowser can be installed. In their turn, remote laboratories hosted on Labicom are web applications that laboratory users can access from web-browsers. Thus, users are able to work with unique or otherwise dangerous experiments and laboratories in leading technical schools globally.

It is cross-platform (Windows, iOS, Mac, Android, UNIX), works on desktop and mobile devices and doesn't require any external plug-ins like Java, Flash, Unity or Silverlight. From the point of view of laboratory administrators Labicom is not only a web site but also a component integrated into their software for direct communication with Labicom web-server. During demonstration session we will show Labicom operation on Windows laptop, on one of Apple devices and on Android tablet.

\section{INTERNET SECURITY AND ACCESSIBILITY}

Access to laboratory resources is granted through secured internet connection (green address bar in the browser).

By encrypting all the communication with SSL and being verified by verification authority Labicom assures its users that they can safely work in this system.

Regardless of the complexity behind the scenes Labicom sends to browser only HTML code with some JavaScript and CSS. It means that it is accessible to all potential users because presently browsers are installed even on mobile phones. Since HTML5 is best supported on Google Chrome, it is recommended to use this browser but it's only a matter of browser compatibility with HTML5 standards. Internet Explorer is still not recommended and all other browsers are somewhere in between.

\section{REMOTE AND ViRTUAL LABS Demos}

Remote Laser Laboratory (RLL) at BMSTU provides remote and virtual experiments (figure 1) with a solidstate pulse laser $\mathrm{Nd}$ :YAG (neodymium-doped yttrium aluminum garnet $\mathrm{Nd}: \mathrm{Y}_{3} \mathrm{Al}_{5} \mathrm{O}_{12}$ ). It allows investigating free-running generation and Q-modulation modes. Time domain, energy and spatial characteristics of solid-state laser are provided for studying and experimenting with. Mode of laser operation and its parameters are fully controlled remotely via electronic and mechatronic devices that have their "virtual" correspondences in the graphical user interface. Students may use results simulated with special software as initial inputs for their experiments, and then compare theoretical and real-life values.

Global Navigation Satellite Systems (GNSS) Laboratory at BMSTU provides engineering educational remote 


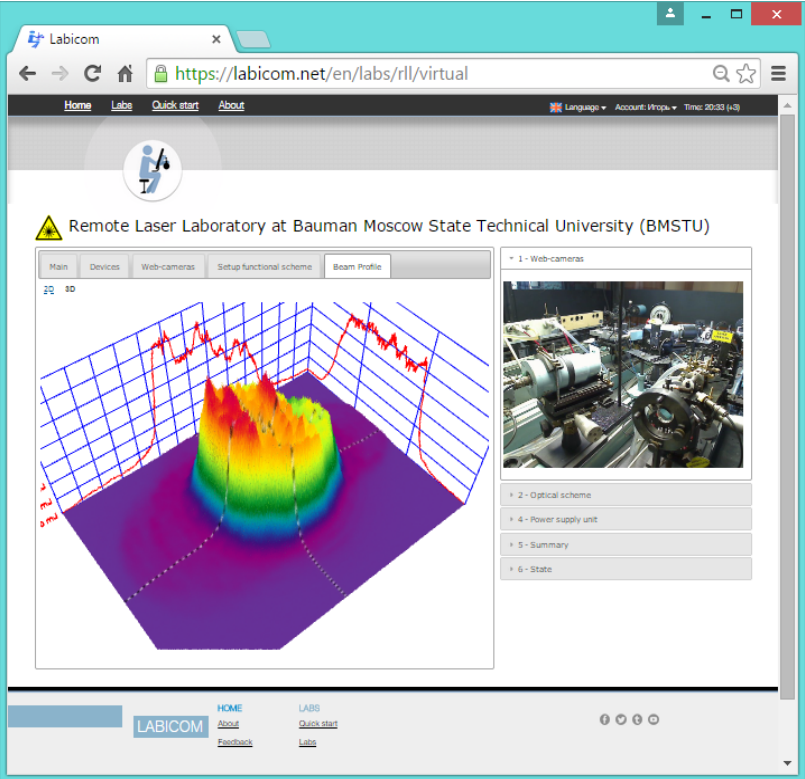

Figure 1. Graphical user interface of the RLL web-client in the webbrowser.

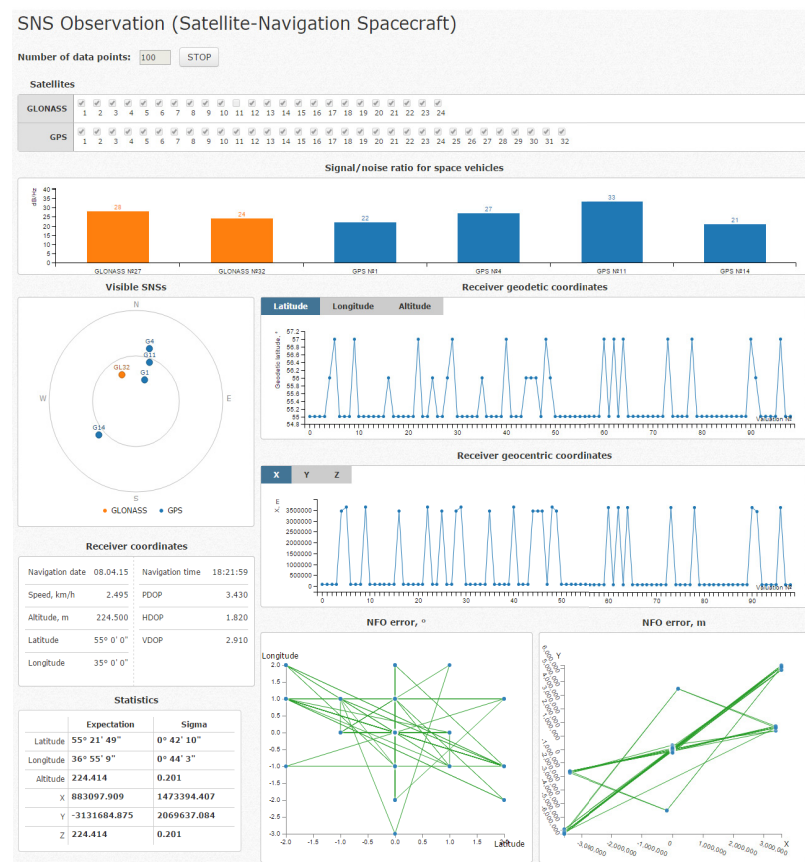

Figure 2. Graphical user interface of the GNSS web-client in the webbrowser

experiments with GLONASS and GPS navigation systems (figure 2). Users can choose various constellations of satellites and investigate special characteristics and appropriate statistics.

The Microwave Amplifier Laboratory (figure 3, 4) was developed by Labicom with Keysight instruments and deployed to two separate locations.

\section{CONCLUSIONS}

Current increasing demand for e-learning and maturation of Internet technologies create an unprecedented opportunity to virtualize laboratories of various kinds. In this paper we showed that the software part of three very different laboratories can be built with the same set of

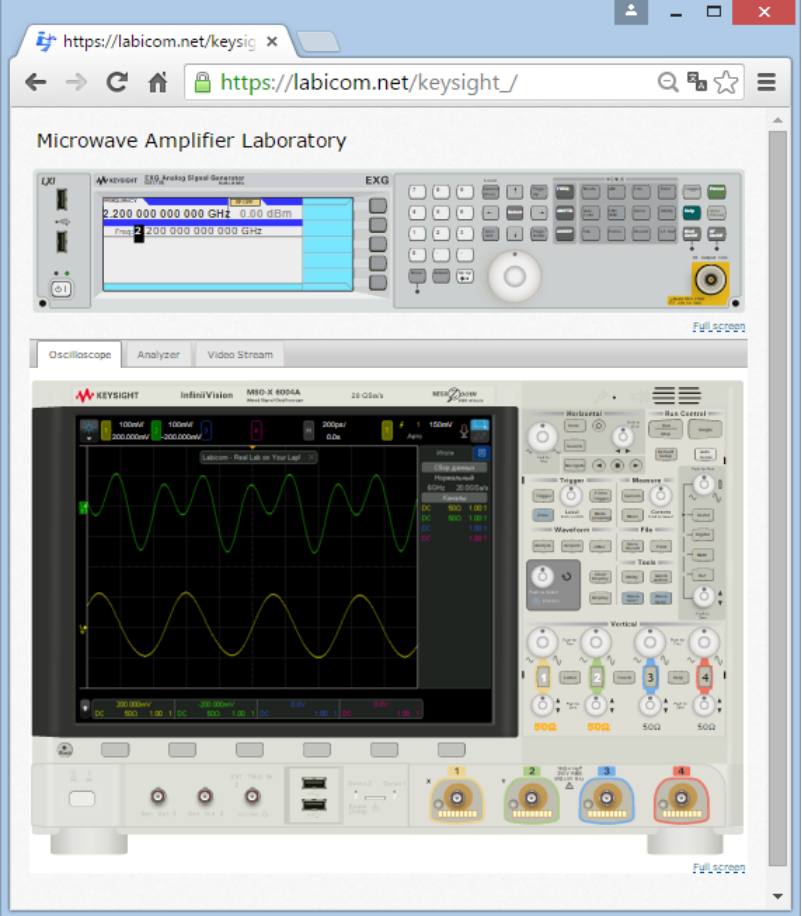

Figure 3. Graphical user interface of the Microwave Amplifier Laboratory (Oscilloscope Tab).

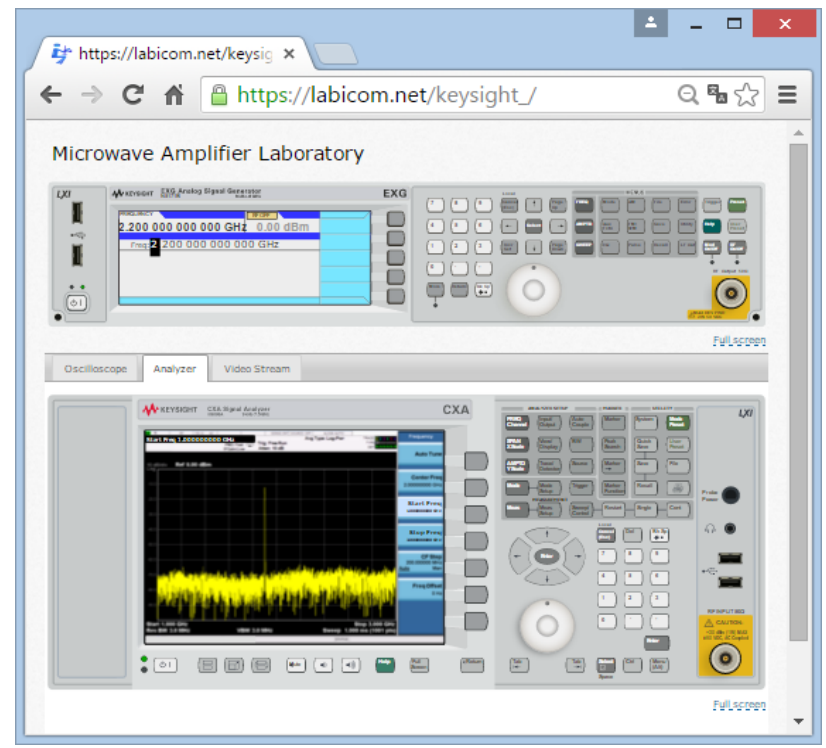

Figure 4. Graphical user interface of the Microwave Amplifier Laboratory (Analyzer Tab).

tools, the same API and infrastructure. Universities benefit from remote lab platforms like Labicom because university teams can focus on experiment-specific features while the platform can provide them with lab server templates, network integration tools (Labicom Connect), specialized LMS and ready-to-use infrastructure.

\section{REFERENCES}

[1] I. Titov "Labicom.net - the on-line laboratories platform: Optimal solution for deploying cost-effective remote and virtual laboratories" in Proc. IEEE EDUCON 2013 conference, March 13-15, 2013, Berlin, Germany, pp. 1137-1140, DOI: http://dx.doi.org/10.1109/EduCon.2013.6530251 
[2] LabicomConnect - LabVIEW plugin for putting remote lab online. [Online]. Available: https://labicom.net/tools/connect (retrieved 18.09.2015)

[3] I. Titov, O. Smirnova, A. Glotov and A. Golovin Remote Laser Laboratory: First Demonstration (Worldwide substitution for laser engineering lab) // International Journal of On-line Engineering (IJOE), Fabruary 2012, vol. 8, Special issue 1: exp.at'11, PP. 1011 DOI: http://dx.doi.org/10.3991/ijoe.v8iS1.1891.

[4] A. Glotov et al. "Remote Laser Laboratory at BMSTU: Browserbased solution" in Proc. ExpAT 2013 conference, 18-20 September 2013, Coimbra, Portugal, pp. 94-98, DOI: http://dx.doi.org/10.1109/ExpAt.2013.6703037

[5] I. Vlasov et al. "Global navigation satellite systems (GNSS) remote laboratory at BMSTU" in Proc. ExpAT 2013 conference, 18-20 September 2013, Coimbra, Portugal, pp. 64-67, DOI: http://dx.doi.org/10.1109/ExpAt.2013.6703031

\section{AUTHORS}

Igor Titov is Chief Technology Officer, R\&D Department, Labicom, Moscow, Russia (igor.ev.titov@gmail.com)

Alexander Glotov, Igor Vlasov and Jakov Mikolnikov are with the Radioelectronic Systems and Devices Dept., Bauman Moscow State Technical University (BMSTU), Moscow, Russia (aglotov@mail.ru, vlasovbmstu@mail.ru, yakovm@mail.ru).

Submitted 22 September 2015. Published as resubmitted by the authors 16 November 2015. 